\title{
Article \\ Recycled Tire Rubber in Additive Manufacturing: Selective
Laser Sintering for Polymer-Ground Rubber Composites
}

\author{
Antoniya Toncheva, Loïc Brison, Philippe Dubois (D) and Fouad Laoutid * (D)
}

Polymeric and Composite Materials Unit, Materia Nova Research Center, University of Mons UMONS, Nicolas Copernic 3, 7000 Mons, Belgium; antoniya.toncheva@materianova.be (A.T.);

loic.brison@materianova.be (L.B.); philippe.dubois@umons.ac.be (P.D.)

* Correspondence: fouad.laoutid@materianova.be; Tel.: +32-65-55-49-78

Citation: Toncheva, A.; Brison, L.; Dubois, P.; Laoutid, F. Recycled Tire Rubber in Additive Manufacturing Selective Laser Sintering for Polymer-Ground Rubber Composites. Appl. Sci. 2021, 11, 8778. https:// doi.org/10.3390/app11188778

Academic Editor: Mehrshad Mehrpouya

Received: 26 August 2021

Accepted: 17 September 2021

Published: 21 September 2021

Publisher's Note: MDPI stays neutral with regard to jurisdictional claims in published maps and institutional affiliations.

Copyright: (c) 2021 by the authors. Licensee MDPI, Basel, Switzerland. This article is an open access article distributed under the terms and conditions of the Creative Commons Attribution (CC BY) license (https:// creativecommons.org/licenses/by/ $4.0 /)$.

\begin{abstract}
Natural and synthetic rubber is gaining increased interest in various industrial applications and daily life sectors (automotive industry, acoustic and electrical isolators, adhesives, impermeable surfaces, and others) due to its remarkable physicomechanical properties, excellent durability, and abrasive resistance. These great characteristics are accompanied by some recycling difficulties of the final products, particularly originated from the tire waste rubber industry. In this study, recycled tire rubber was incorporated in polymer matrices using selective laser sintering as 3D printing technology. Two polymers were used-polyamide and thermoplastic polyurethane, for their rigid and elastomeric properties, respectively. Polymer composites containing various tire powder amounts, up to $40 \mathrm{wt}$ \% , were prepared by physical blending. The final materials' morphological characteristics, mechanical properties, and thermal stability were evaluated. The proposed ambitious additive manufacturing approach looked over also some of the major aspects to be considered during the 3D printing procedure. In addition, examples of printed prototypes with potential applications were also proposed revealing the potential of the recycled tire rubber-loaded composites.
\end{abstract}

Keywords: recycled tire rubber; polymer composites; polyamide; thermoplastic polyurethane; additive manufacturing; 3D printing

\section{Introduction}

The science and engineering of polymer materials have been greatly impacted by the development of the radically induced vulcanization process by Charles Goodyear in 1844 [1], allowing the fabrication of crosslinked elastomeric products between sulfurcontaining compounds. This technological advancement resulted in robust and insoluble materials defined as infusible thermosets unable to undergo reprocessing, opposite to conventional thermoplastics. The automobile industry is one of the most demanding sectors of rubber material, from both natural and synthetic resources. Currently, the annual global production is estimated at 1.4 billion units, corresponding to 17 million tons of used tires [2]. From engineering and chemical points of view, such single-use tires are actually a complex structure, containing a rich palette of chemical compounds (rubber, oils, antioxidants, colorants, reinforcing agents, carbon black, organosulfur-silica, fibrous reinforcing agents, and other additives), making the used tires recycling a real challenge with important environmental impact [3]. The rubber properties can be further reinforced by the incorporation of various additives (stabilizers, antioxidants, and antiozonants), leading to highly resistant materials in terms of photochemical decomposition, thermal degradation, or biodegradation [4-6]. In this meaning, the main concern is relative to the increased risk of soil and water contamination with metals and numerous additives, as well as air pollution with toxic gases released from difficult to quench tire fires.

During the years, important efforts were made to go one step further in the development of a legal framework for sustainable management of the used tires, with new opportunities of commercial value for such environmentally problematic materials. It is 
worth mentioning that tire rubber (TR) waste finds already an interesting application in effective conversion to energy, artificial reef, playground equipment, erosion control, highway crash barriers, pyrolysis, and is considered as an excellent energy and fuel source for its great heat value $[2,7]$. A promising approach to highlight the caoutchouc waste properties, presents its blending with different polymers to produce freshly designed composites. In fact, the main interest in the thermoset industry is focused on the improvement of the material's toughness on the thermoplastic aspect. The main objective was the fabrication of thermoplastic elastomers, while on the rubber side, the TR is used as a cheap filler. Today, TR-loaded polymer materials already find an application in various daily life sectors, such as athletic tracks, playground surfaces, asphalt mix, shock absorption, abrasive resistance surfaces at relatively low production costs [5]. Often, the incorporation of the TR in polymers is accompanied by a decrease in the final material mechanical properties due to insufficient noncovalent interface interactions between the rubber particles and the matrix. This requires additional surface pre-treatment of the rubber phase for improved interfacial adhesion between the blend components and a successful combination of the polymer properties and the rubber characteristics. Therefore, a mild protocol to reuse the organic fraction in the used automotive tires was described for new elastomer production, and this in combination with other sulfur-crosslinked rubbers by reductive silylation of the disulfide bond [8]. Adding natural modified oils (e.g., soybean oil) to the TR is another alternative to the commonly used petroleum plasticizers that can further increase the mechanical and aging resistance properties of the final devices [9]. Blending functionalized polymers, such as maleic anhydride-modified polypropylene (PP), with devulcanized recycled rubber is also an appropriate solution for the generation of nanomaterials with improved thermal stability and mechanical properties, with interesting, recycled rubber reuse and reduced cost [10].

The last trends in TR waste valorization, where complex multi-step chemical procedures and organic solvents are avoided, present the additive manufacturing techniques for their fast-prototyping advantages of devices with desirable final properties. Furthermore, the $3 \mathrm{D}$ printing technology is also considered as an eco-friendly beneficial approach for printed materials with complex geometries that can be partly or entirely made of recycled resources, without the use of mold tooling. For example, recycled ground TR modified with 3-(trimethoxysily)propyl methacrylate was used as ink in the elastomeric matrix for direct printing. The resulted composites were defined as cheaper compared to the equivalent polymer specimens, with mechanical properties close to the molded references [11]. Dropon-demand-based inkjet was used for the fabrication of multilayer latex-based materials loaded with micronized end-of-life tire rubber, with preserved Young's modulus of the printed specimens [12]. Between the available additive manufacturing technologies, selective laser sintering (SLS) is one of the most attractive from industrial and academic points of view. SLS is offering an additional level of flexibility in terms of devices prototyping with desired composition, morphological and physicomechanical performances at relatively high loading ratios of the used micro- and nanofillers. It is already used in the fabrication of materials with conferred optical properties, thermal conductivity, heat resistance, flame retardancy, biocompatibility by the incorporation of aluminum powder [13], carbon nanofibers [14], nanosilica [15], clay [16], glass beads [17], and hydroxyapatite [18].

Mechanical downsizing of TR waste is a process often applied to granulate the tire waste to the called ground rubber tire, which can be further devulcanized to become reclaimed tire rubber powder, making it suitable for blending with different polymer matrices [19]. In this aspect, smaller rubber particles are preferable, offering the possibility to obtain better dispersions within the polymer material. In addition, the greater surface area of smaller particles offers the possibility to enhance the interface adhesion between the rubber domains and the polymer matrix for decreased phase separation effect. In the literature, it was found that rubber particles sized under $500 \mu \mathrm{m}$ allow the fabrication of materials with acceptable balance in terms of mechanical properties based on PP [20], high density polyethylene (HDPE) [21], and ethylene vinyl acetate copolymer (EVA) [22] 
polymers. An improvement in the material impact strength (about 20\%) was also obtained after incorporation of particles with an average size of $420 \mu \mathrm{m}$ in PP thermoplastic blends, in contrast to materials containing 1.2 and $2.4 \mathrm{~mm}$ sized ones [23].

In the present study, we proposed a one-step approach for the fabrication of TR waste-loaded polymer composites by 3D printing using SLS. For this purpose, two kinds of polymer matrices were used: polyamide (PA12) and thermoplastic urethane (TPU) for their rigid and elastomeric properties, respectively. The TR particles morphology and composition were first evaluated, as well as their dispersion ability at different amounts $(10,15,30$, and $40 \mathrm{wt} \%)$ within the printed device volume. Special attention was paid to the material thermal stability and mechanical properties (tensile and impact tests) and the surface resolution as a part of the quality validation procedure. As a final touch, different prototypes were proposed paving the way to new horizons in the TR waste reuse and valorization as a solution for the prolongated half-life of the rubber waste.

\section{Materials and Methods}

\subsection{Materials}

For the production of the composite materials, two types of polymers were used: polyamide 12 (PA12; polymer powder particle size between 20 and $100 \mu \mathrm{m}$ ) and thermoplastic polyurethane (TPU or Flexa black; polymer powder particle size between 20 and $105 \mu \mathrm{m})$, both purchased from Sinterit (Poland). Synthetic truck tire powder ( $98 \%$ of the rubber particle size under $150 \mu \mathrm{m}$ ) was kindly provided by Recytyre asbl (Belgium).

\subsection{SLS Printing Conditions}

The specimens were prepared using an SLS Lisa 3D printer (Sinterit, Poland), equipped with an IR laser diode source of $5 \mathrm{~W}$ and wavelength of $\lambda=808 \mathrm{~nm}$. Neat PA12 or TPU powders, as well as polymer/TR powder physical blends, were prepared, and the TR amount was chosen as 10, 20,30, or $40 \mathrm{wt} \%$ with respect to the polymer matrix weight. For the preparation of each of the polymer/TR blends, both the polymer and the TR powder were gradually mixed until achieving the desired ratio. At the end of this procedure, the blends were once more subjected to a series of mixing for $15 \mathrm{~min}$ in order to ensure the homogeneity of the composition. The quantity of the blends for the successful SLS printing was fixed to $1 \mathrm{~kg}$. During the printing procedure, the layer thickness was set at $125 \mu \mathrm{m}$ (minimum allowed layer $\mathrm{Z}$ height of the apparatus is $75 \mu \mathrm{m}$ while the maximum is $175 \mu \mathrm{m}$ ) in order to ensure suitable final product resolution while preventing TR particle selection during the layer-by-layer procedure by the recoater. For the TPU specimens, two printing modes were also tested: flex and rigid mode, as defined in the SLS printer software. At the end of the printing process, the final objects were carefully cleaned with a brush and exposed to compressed airflow at low pressure to take off the residual non-adhered surface powder.

\subsection{Materials Characterization}

The morphological characteristics of the TR particles and the printed specimens were studied by scanning electron microscopy (SEM, Hitachi SU8020 -100 V-30 kV, samples covered with a thin conductive layer) and optical microscopy (Leica, DMS 1000), and the particle dimensions were measured with Image J software, while measuring at least 100 individual particles for statistical soundless. Elemental analysis of the TR particles was carried out with EDX mode of SEM apparatus (acc voltage of $10 \mathrm{kV}$ ). The thermal stability of the samples and the loaded TR content were assessed by thermogravimetric analysis (TGA) in the range from 25 to $800^{\circ} \mathrm{C}$ (samples weight of $10 \mathrm{mg}$ ) while applying a heating rate of $20^{\circ} \mathrm{C} / \mathrm{min}$ under nitrogen flow (Mettler Toledo apparatus). The mechanical properties of 3D printed PA12(/TR), and TPU(/TR) materials were characterized using a Lloyd Instruments machine (LR10, $10 \mathrm{~mm} / \mathrm{min}$ ) in the case of the tensile tests (dog boneshaped samples with respect to ASTM 638 standard), while a Ray-Ran 2500 pendulum impact tester and a Ray-Ran 1900 notching apparatus were used in Izod mode for the 
impact strength tests (V-notched rectangular samples with respect to ASTM D256 standard). For all of the tensile and impact tests, the printed samples were previously conditioned for $48 \mathrm{~h}$ at $21^{\circ} \mathrm{C}$. The porosity degree of the TPU/(/TR) printed samples was evaluated by taking into account the density of the materials and comparing the samples' weight with the values recorded for the molded samples with the same chemical composition. The injected samples were obtained using DSM mini injection molding apparatus.

\section{Results}

In the present study, we proposed a one-step approach to develop TR-loaded polymer materials, such as PA12 and TPU, using SLS as a flexible additive manufacturing technology. In brief, in this method, a laser power source to sinter powdered materials (e.g., fine polymer powder, metal, ceramics, and others) is used to create the final solid structure upon a defined 3D model. Of importance for the suitable quality of the final object is the powder flow, which can impact the printed device's physicomechanical properties, as well as the fine surface finish. In this aspect, the thin powder layer consistent deposition is crucial, without particle selection during the layer-by-layer printing procedure. In fact, the particles' dimensions should be smaller than the layer thickness, thus ensuring the homogeneous composition of the powdered material during laser scanning. A schematic presentation of the SLS working principle is provided in Figure 1.

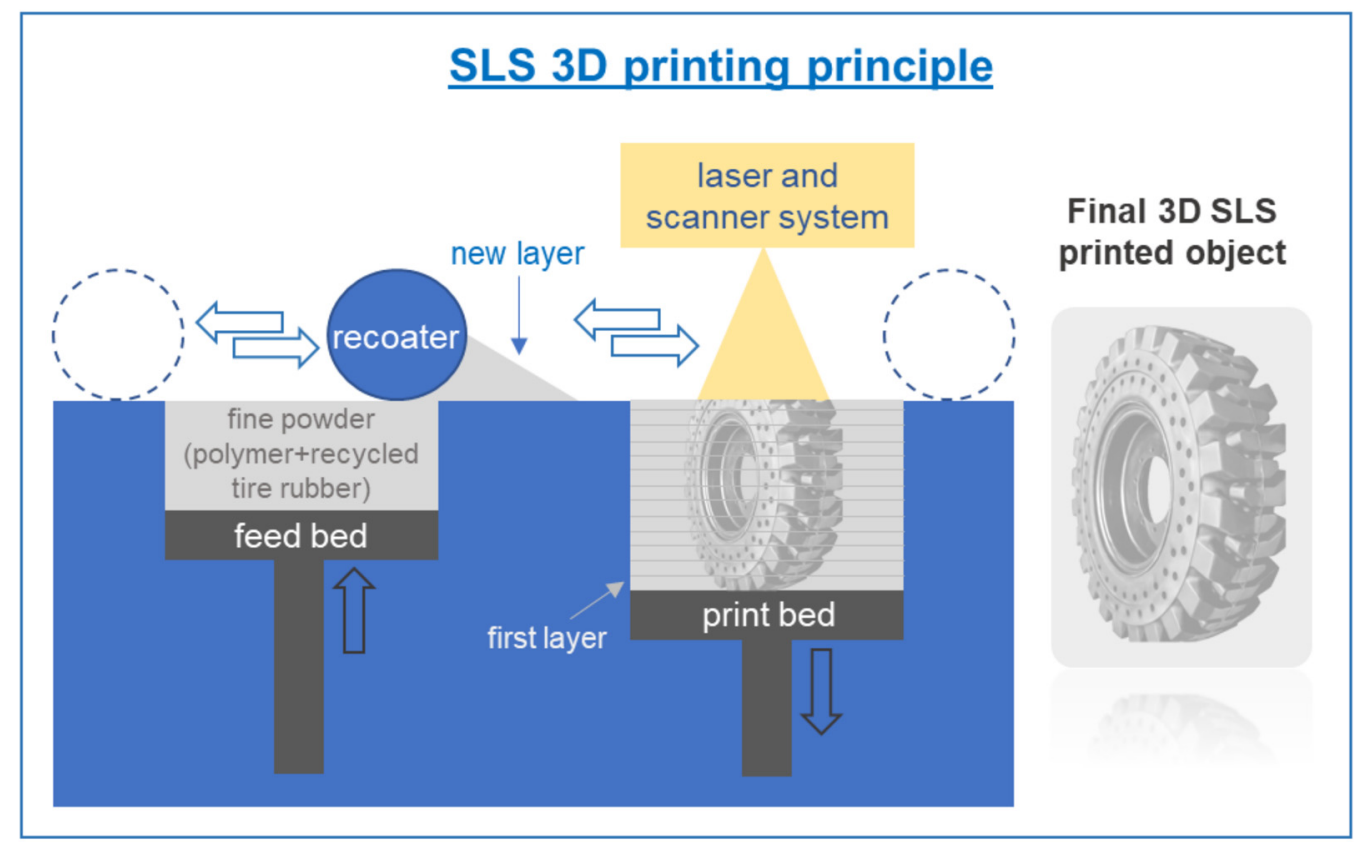

Figure 1. Schematic presentation of the SLS printing process.

Here, for the specimen fabrication, a layer thickness of $125 \mu \mathrm{m}$ was used, defined as the optimal working thickness without selection of the TR particles, suitable dispersion of the rubber domain, and final object resolution. The TR particles dimensions were studied by SEM, and the particle size was found to be about $98 \%$ under $150 \mu \mathrm{m}$, with a major size distribution between 60 and $100 \mu \mathrm{m}$, as presented in Figure 2. Generally, in laser sintering, particle dimensions around $45-90 \mu \mathrm{m}$ are considered optimal in size [24]. In addition, particles smaller than $45 \mu \mathrm{m}$ are often considered as a generator of static forces, making the printing process difficult. Moreover, polymer particles with dimensions in the range between 150 and $200 \mu \mathrm{m}$ (e.g., polylactic acid) or even between 425 and $600 \mu \mathrm{m}$ (HDPE) proved to lead to the fabrication of porous devices with rough surfaces [24]. 


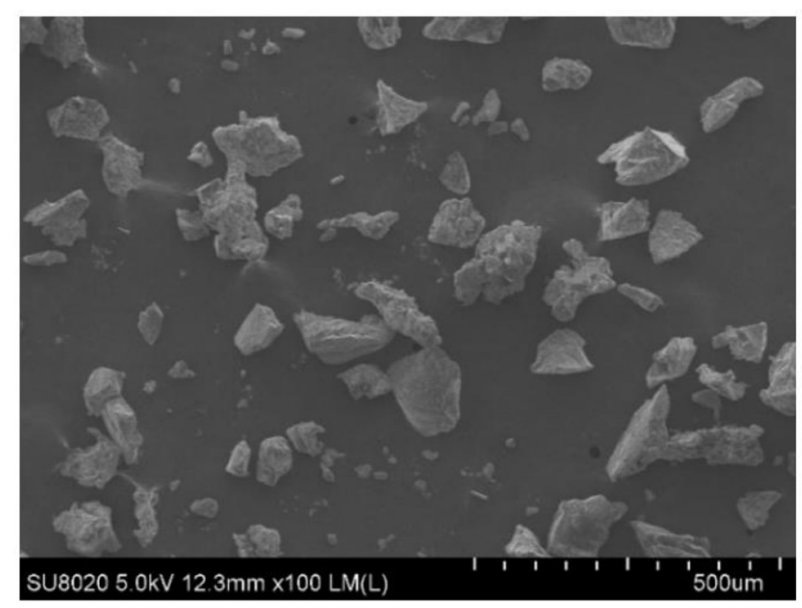

A

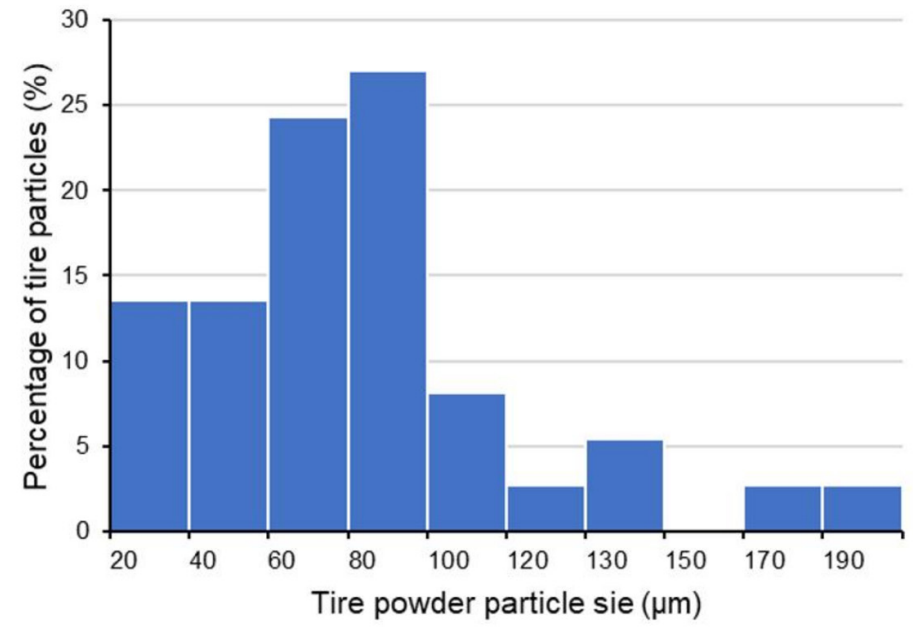

B

Figure 2. SEM micrograph of micronized TR powder (A) and TR particle size distribution (B).

\subsection{SLS 3D Printing of PA12-Based Materials Containing Recycled TR}

A series of PA12-based materials loaded with different amounts of TR (10, 20, and $30 \mathrm{wt} \%$ with respect to the polymer matrix) were produced by SLS 3D printing. Increasing the TR content up to $40 \mathrm{wt} \%$ led to a clear decrease in the printed parts' shape resolution and printing quality. The resulted materials were identified as PA12, PA12/TR10, PA12/TR20, and PA12/TR30, where the TR content was $0,10,20$, and $30 \mathrm{wt} \%$, respectively. The morphological studies of the TR particles revealed irregular surface with complex elemental composition, as revealed by EDX analysis: $39.8 \%$ for $\mathrm{C}, 44.2 \%$ for $\mathrm{O}, 0.2 \%$ for $\mathrm{F}, 6.8 \%$ for $\mathrm{Mg}, 0.1 \%$ for $\mathrm{Al}, 8.6 \%$ for $\mathrm{Si}, 0.2 \%$ for $\mathrm{S}$ and $0.2 \%$ for $\mathrm{Zn}$ (Figure 3 ).

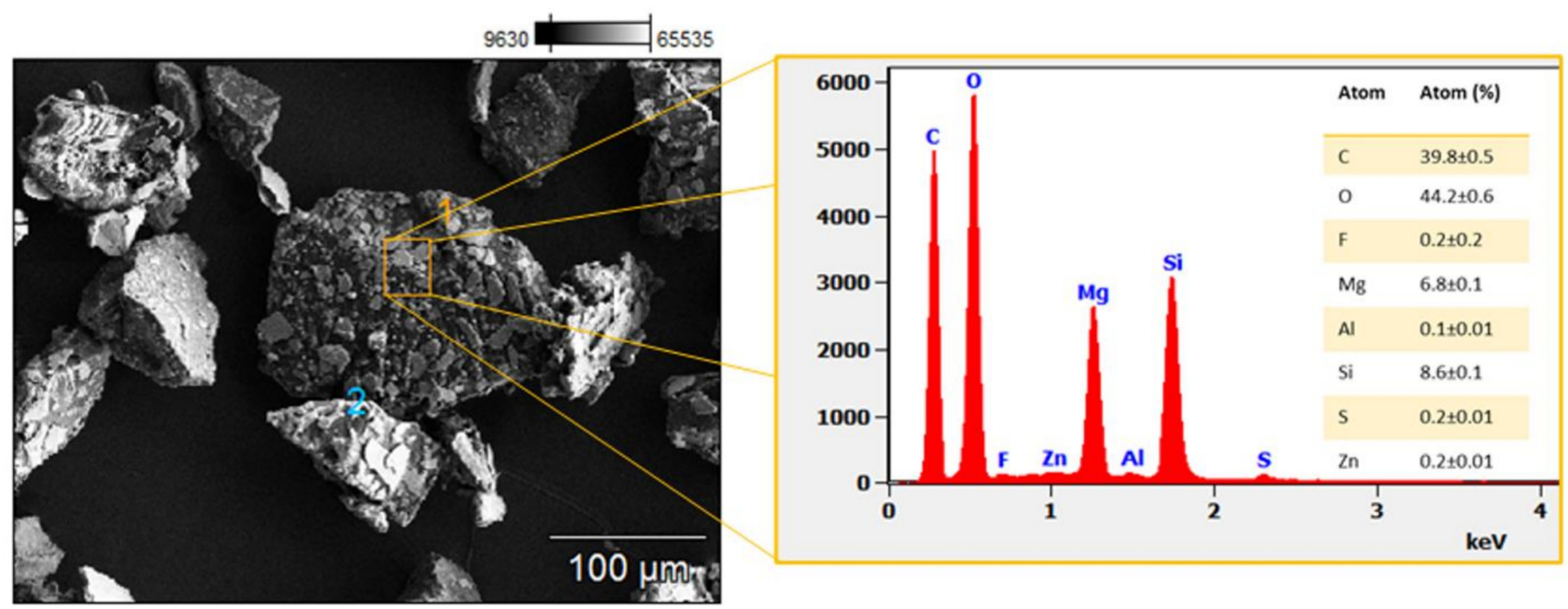

Figure 3. SEM micrograph of TR microparticles surface and related EDX analysis.

TGA analysis was used to evaluate the thermal stability of pristine PA12, TR powder, and the corresponding composites. As presented in Figure 4, TR powder presented lower thermal stability compared to pristine PA12, and TR incorporation into PA12 induced a decrease in the onset values of the polymer composites degradation temperature (Td). In fact, at $5 \%$ weight loss during the TGA analysis, a decrease in the $\mathrm{Td}$ values was noticed from $419{ }^{\circ} \mathrm{C}$ for the pristine PA12 to 400,372 , and $365^{\circ} \mathrm{C}$ in the presence of 10,20 , and $30 \mathrm{wt} \%$ TR powder, respectively (Table 1). This result is important and demonstrates that the incorporation of high TR loading could strongly impact the composite thermal 
stability. Moreover, the incorporation of TR powder also affected the Td that decreases slightly between 465 and $470{ }^{\circ} \mathrm{C}$, depending on the incorporated amount of rubber powder (Table 1). The obtained results guided us to limit the maximum loaded TR powder amount to $30 \mathrm{wt} \%$. On the other side, it was found that the thermal stability of the PA12 was not significantly impacted after the printing process: Td before and after the printing step (IR laser diode irradiation, $5 \mathrm{~W}$ and $\lambda=808 \mathrm{~nm}$ ) was 451 and $458^{\circ} \mathrm{C}$, respectively.
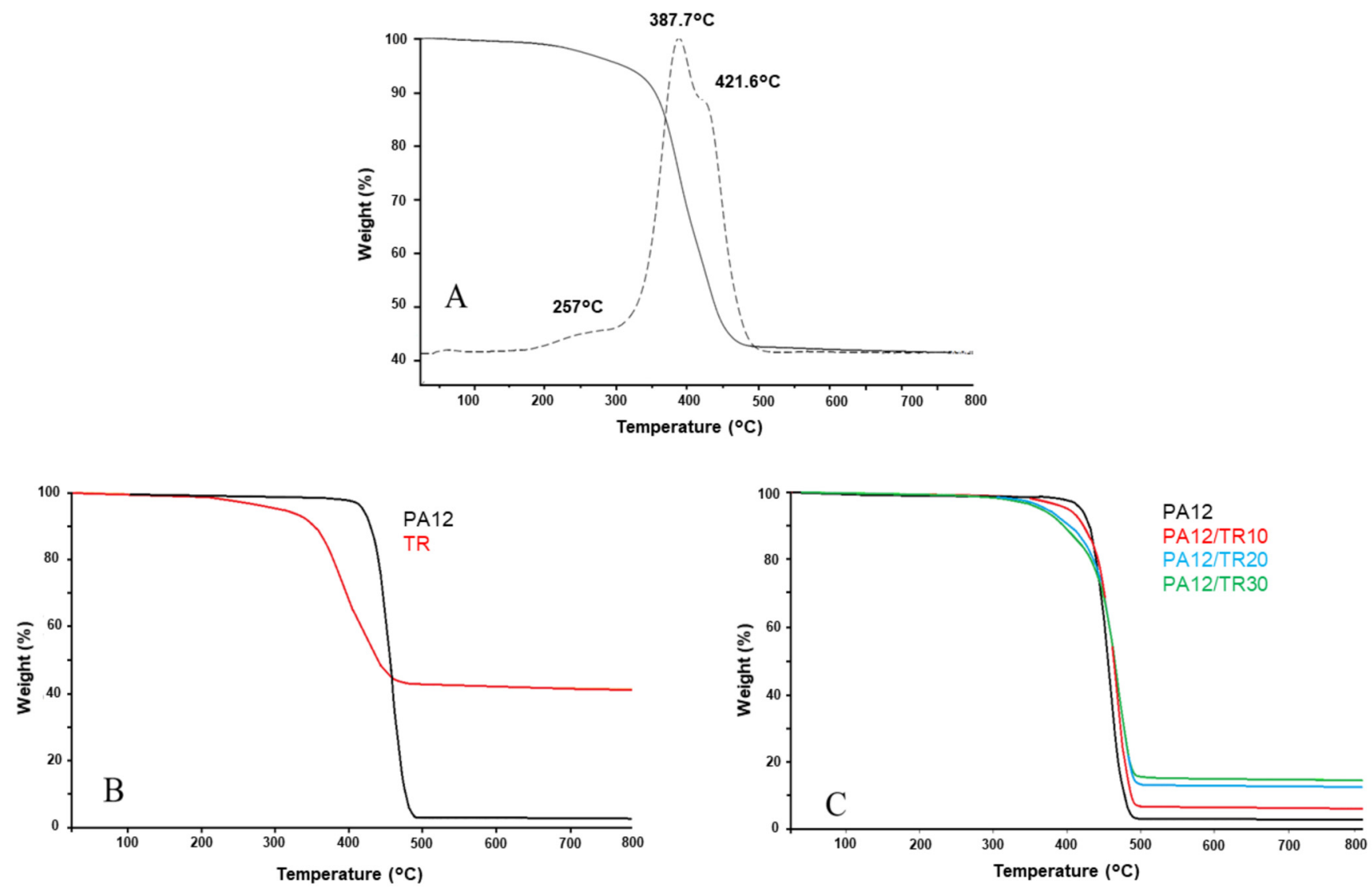

Figure 4. TGA thermograms of TR powder (A), PA12 printed sample and TR powder (B), and PA12(/TR) printed samples (C).

Table 1. TGA analysis of TR, PA12/TR-based materials, and TR content in the printed materials.

\begin{tabular}{|c|c|c|c|c|}
\hline Sample & $\operatorname{Td}\left({ }^{\circ} \mathrm{C}\right)$ & $\begin{array}{c}\text { Td after } 5 \mathrm{wt} \% \text { Weight } \\
\text { Loss }\left({ }^{\circ} \mathrm{C}\right)\end{array}$ & Residue at $800^{\circ} \mathrm{C}(\%)$ & $\begin{array}{l}\text { TR Amount in the } \\
\text { Printed Samples (\%) }\end{array}$ \\
\hline TR & 385 and 426 & 308 & $41.2 \pm 1.3$ & n.a. \\
\hline PA12 powder & 451 & 412 & $2.2 \pm 0.1$ & n.a. \\
\hline PA12 printed & 458 & 419 & $2.5 \pm 0.1$ & n.a. \\
\hline PA12/TR10 & 466 & 400 & $6.1 \pm 0.3$ & $9.0 \pm 0.4$ \\
\hline PA12/TR20 & 468 & 372 & $12.2 \pm 0.5$ & $24.3 \pm 0.9$ \\
\hline PA12/TR30 & 468 & 365 & $14.4 \pm 0.7$ & $29.8 \pm 1.3$ \\
\hline
\end{tabular}

At the end of the TGA analysis of TR powder, a mineral residue of $41.2 \%$ at $800{ }^{\circ} \mathrm{C}$ was obtained, while for PA12, this residue was close to $2.5 \%$. These data allowed us to determine the amount of TR in each of the printed composites by considering the final residue. For example, in the case of the printed PA12/TR10, PA12/TR20, and PA12/TR30 samples, it was found that the incorporated TR content was $9 \pm 0.4 \mathrm{wt} \%, 24.3 \pm 0.9 \mathrm{wt} \%$, and $29.8 \pm 1.3 \mathrm{wt} \%$, respectively (Table 1 ). This confirmed the suitable distribution of the TR powder within the polymeric matrix and validated the printing procedure as suitable for the fabrication of printed materials with desired rubber composition. 
In addition to the TR particle dimensions, several studies demonstrated that the relative content in rubber particles greatly affects the composite final properties. Therefore, particle loading higher than $50 \%$ is often related to unsatisfying physicomechanical characteristics. The general tendency is that the tensile and the impact strength performances are deteriorated with the addition of the rubber particles and even more with the increase in average particle size. This is often accompanied by poor interfacial adhesion between the polymer matrix and the rubber domains, leading to both high interface tension and failure cracks. This was attested in several thermoplastic matrices containing recycled TR powders. For example, a clear decrease in the tensile modulus and elongation at break up to $93 \%$ in HDPE blends [25]. The same material behavior was found while using recycled HDPE containing $50 \mathrm{wt} \%$ TR [26], in PP containing $30 \mathrm{wt} \%$ TR [20], and in EVA containing $20 \mathrm{wt} \%$ TR [22].

The stress-strain curves of the developed PA12(/TR) samples are presented in Figure 5A. It was found that Young's modulus of the PA12 specimens was $1270 \pm 71 \mathrm{MPa}$ with $7 \%$ elongation at break (Table 2). The incorporation of the TR powder, up to $20 \mathrm{wt} \%$, did not lead to a significant deterioration of the composite mechanical properties. In fact, both Young's modulus and elongation at break remained close in values to those of the pristine PA12 in the case of TR loading of 10 and $20 \mathrm{wt} \%$. The Young's modulus values were: $1280 \pm 12 \mathrm{MPa}$ and $1210 \pm 20 \mathrm{MPa}$ for PA12/TR10, PA12/TR20, respectively. Lower values were obtained in the case of the PA12/TR30-1110 $\pm 100 \mathrm{MPa}$. A slight decrease in the strain at break values was recorded at $5.8 \pm 0.3 \%, 5.0 \pm 0.2 \%$, and $5.4 \pm 0.2 \%$ for PA12/TR10, PA12/TR20, and for PA12/TR30 as compared to unfilled PA12. The presence of tire phase also induced some decrease in the stress at yield from $37 \mathrm{MPa}$ for pristine PA12 down to $30 \mathrm{MPa}, 27.5 \mathrm{MPa}$, and 23.5 MPa for 10, 20, and $30 \mathrm{wt} \%$ of loaded TR, respectively. This effect was explained by the softness of the tire powder, which reduces the stiffness of the printed composites.
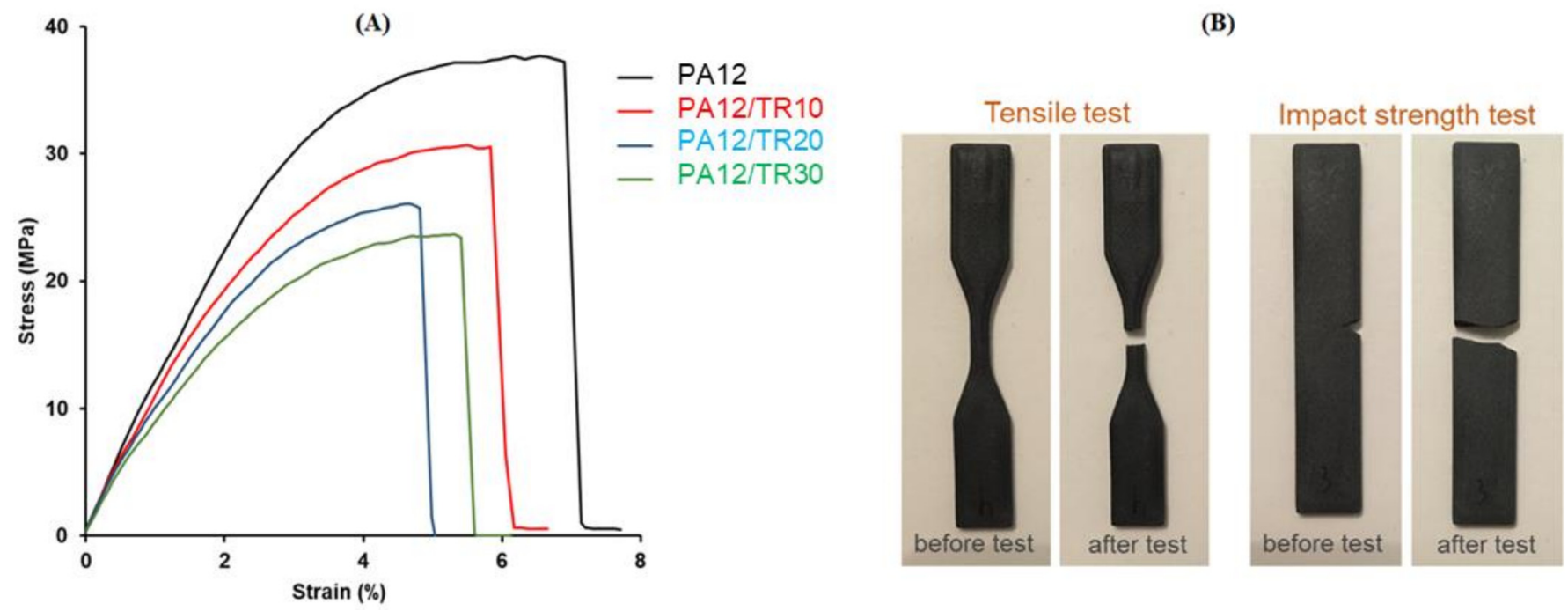

Figure 5. Stress-strain curves of PA12 and PA12/TR samples (A) and digital images before and after tensile and impact strength tests $(\mathbf{B})$.

Table 2. Young's modulus, elongation at break and impact resistance values of PA12(/TR) printed materials.

\begin{tabular}{ccccc}
\hline Sample & $\begin{array}{c}\text { Young's Modulus } \\
\mathbf{( M P a )}\end{array}$ & Stress at Yield (MPa) & $\begin{array}{c}\text { Elongation at Break } \\
\mathbf{( \% )}\end{array}$ & $\begin{array}{c}\text { Impact Resistance } \\
\left(\mathbf{k J} / \mathbf{m}^{\mathbf{2}}\right)\end{array}$ \\
\hline PA12 & $1270 \pm 71$ & $36.7 \pm 0.3$ & $7.0 \pm 0.3$ & $2.3 \pm 0.2$ \\
PA12/TR10 & $1280 \pm 12$ & $30.0 \pm 1.0$ & $5.8 \pm 0.3$ & $2.9 \pm 0.2$ \\
PA12/TR20 & $1210 \pm 20$ & $27.5 \pm 1.5$ & $5.0 \pm 0.2$ & $2.7 \pm 0.2$ \\
PA12/TR30 & $1110 \pm 100$ & $23.5 \pm 2.3$ & $5.4 \pm 0.2$ & $3.0 \pm 0.5$ \\
\hline
\end{tabular}


The positive effect of the soft rubber particles is also verified on the composite impact properties. In fact, the incorporation of TR in PA12 matrix did not induce any fall of the composite impact resistance that is in the opposite slightly increased: from $2.3 \pm 0.2 \mathrm{~kJ} / \mathrm{m}^{2}$ for the PA12 sample up to $3.0 \pm 0.5 \mathrm{~kJ} / \mathrm{m}^{2}$ when $30 \mathrm{wt} \%$ of TR is incorporated (Table 2). Digital images of the printed samples before and after the tensile and impact strength tests are presented in Figure 5B. This result is in suitable accordance with the literature that support similar effects. For example, recycled TR was incorporated in HDPE, where a clear increase in the impact strength was obtained at TR content up to $50 \mathrm{wt} \%$ depending on the type of the used vulcanization agent (sulfur or peroxide), or to the addition of a compatibilizer [27]. However, in this system, the tensile strength was deteriorated (ca. $70 \mathrm{wt} \%$ ) with the increase in the rubber content. The same tendency was reported after adding recycled and grounded TR to PP, where the higher impact strength was found for the sample after the dynamic sulfur vulcanization of the rubber [23].

The suitable mechanical properties obtained in the presence of TR particles may be explained by their relatively small size and elastomeric behavior but also by the suitable level of dispersion. Indeed, SEM analysis of the PA12 sample containing $20 \mathrm{wt} \% \mathrm{TR}$ evidenced fine dispersion of the rubber particles within the polymer matrix (Figure 6). As presented, the lighter gray zones are characteristic of the TR domains, while the darker ones correspond to PA12. Moreover, the defect-free aspect of the printed samples (absence of voids, fractures, cracks) was an additional indication for the suitable interface adhesion between the rubber filler and the polymer, confirming the suitable printability of the powder blend.

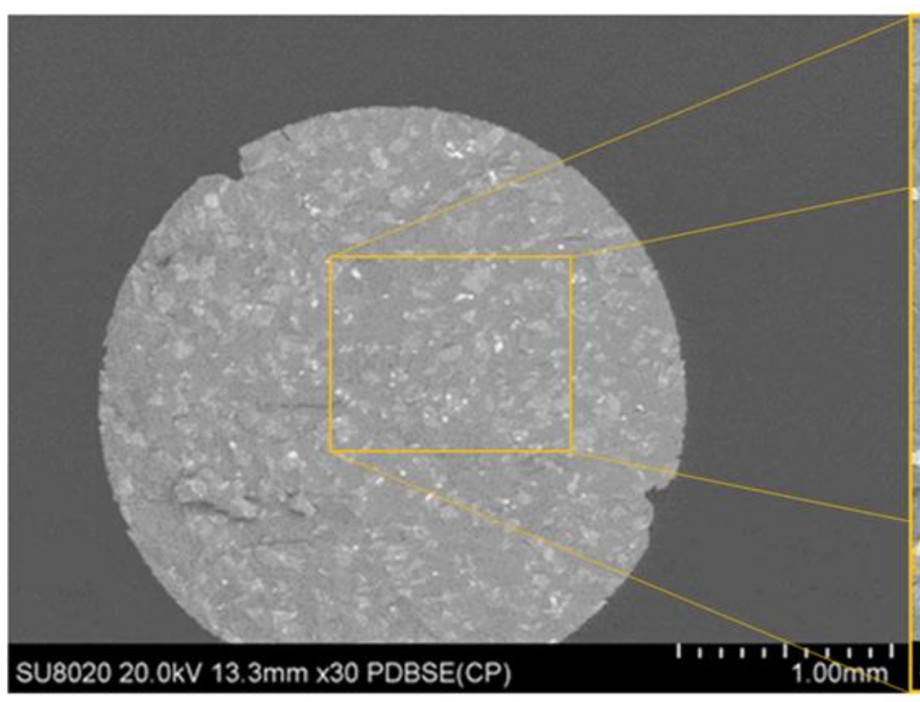

A

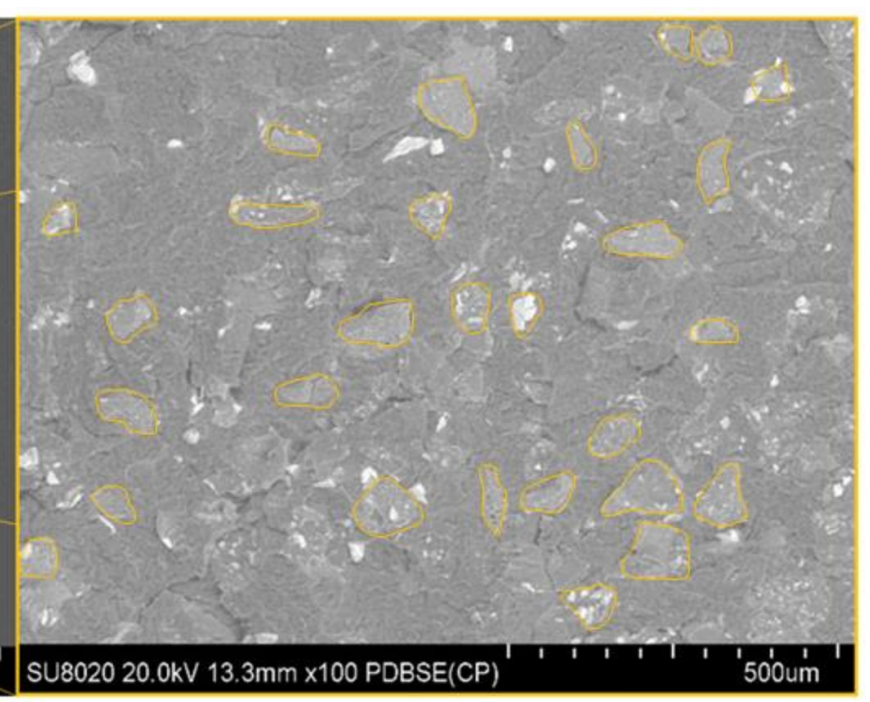

$\mathrm{B}$

Figure 6. SEM micrographs of PA12/TR20 printed sample (A) and a micrograph detail revealing the TR particles distribution within the composite material (TR particles enclosed in orange) (B).

As a concluding remark for this section, the applied SLS additive manufacturing technology allowed the successful production of series of PA12-based materials with a high loading ratio of the recycled TR (up to $30 \mathrm{wt} \%$ ) and fine surface finish. The suitable dispersion of the rubber domains within the printed materials' volume was confirmed by morphological SEM analysis. It was also possible to control and define the amount of the incorporated TR. The thermal stability of the specimens was not significantly impacted. The mechanical properties of the TR-loaded materials demonstrated a slight drop in Young's modulus values ( $5 \%$ for PA12/TR20 sample), some reduction in stress at yield accompanied with a slight increase in the impact resistance. 


\subsection{SLS 3D Printing of TPU-Based Materials Containing Recycled TR}

Going further in the feasibility of the printing process and the valorization of the recycled TR powder, we explored the interest of TR incorporation in the TPU polymer matrix for its soft and elastomeric characteristics. In this series of specimens, the TR content was also fixed at 10, 20, and $30 \mathrm{wt} \%$ with respect to the total polymer content, and the specimens were coded as TPU/TRP10, TPU/TR20, and TPU/TR30.

In contrast to the PA12 composites, the thermal stability of TPU/TR-based samples was not impacted by the addition of the elastomeric filler (Figure 7). In fact, TR powder presented higher thermal stability than the pristine TPU (Figure 7). In the case of here studied TPU, a final residue of about $5 \%$ was collected and corresponded to black fillers used by Sinterit ${ }^{\circledR}$ in order to enhance laser absorption during the printing process. Once more, the residue at the end of the TGA analysis allowed us to evaluate the amount of the incorporated rubber fraction within the produced materials, revealing the successful incorporation of the rubber particles by SLS (Table 3). The TR content was found to be $13 \pm 0.7 \mathrm{wt} \%, 20 \pm 1.2 \mathrm{wt} \%$, and $33.5 \pm 2 \mathrm{wt} \%$ for the TPU/TRP10, TPU/TR20, and TPU/TR30 samples, respectively.

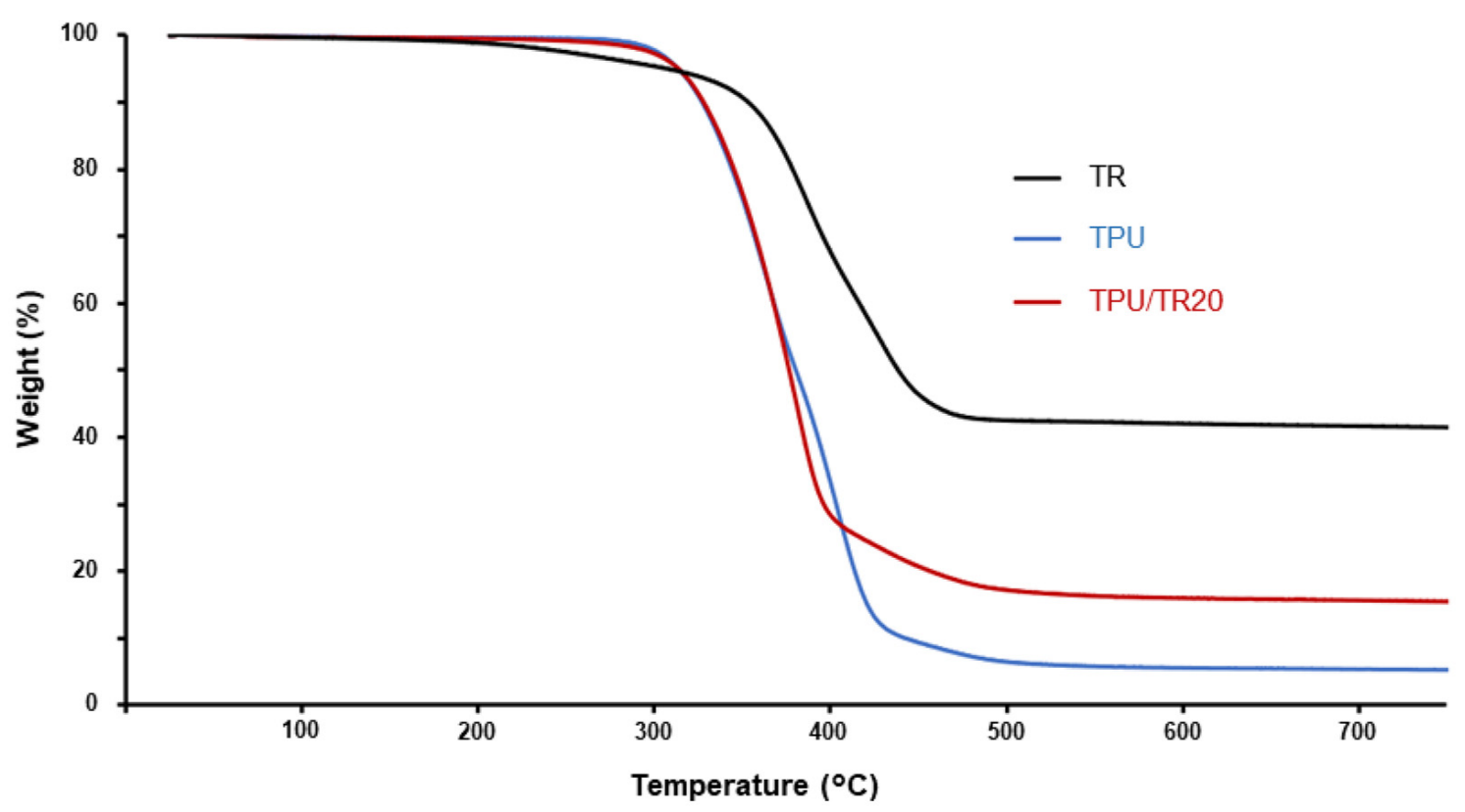

Figure 7. TGA thermograms of TPU, TR, and TPU/TR20 printed samples.

Table 3. TGA analysis of TR, TPU/TR-based samples, and TR content in the printed materials.

\begin{tabular}{|c|c|c|c|c|}
\hline Sample & $\operatorname{Td}\left({ }^{\circ} \mathrm{C}\right)$ & $\begin{array}{c}\text { Td after } 5 \mathrm{wt} \% \text { Weight } \\
\text { Loss }\left({ }^{\circ} \mathrm{C}\right)\end{array}$ & Residue at $800{ }^{\circ} \mathrm{C}(\%)$ & $\begin{array}{l}\text { TR Amount in the } \\
\text { Printed Samples (\%) }\end{array}$ \\
\hline TR & 386 and 426 & 308 & $41.2 \pm 1.3$ & n.a. \\
\hline TPU powder & 378 and 408 & 320 & $5.5 \pm 0.16$ & n.a. \\
\hline TPU printed & 363 and 404 & 313 & $5.1 \pm 0.13$ & n.a. \\
\hline TPU/TR10 & 385 & 314 & $10.3 \pm 0.4$ & $13 \pm 0.7$ \\
\hline TPU/TR20 & 376 & 313 & $15.2 \pm 0.5$ & $20 \pm 1.2$ \\
\hline TPU/TR30 & 373 & 312 & $18.5 \pm 0.9$ & $33.5 \pm 2$ \\
\hline
\end{tabular}

The presence of the TR powder in the TPU induced a serious drop in the composite mechanical properties, as presented in Figure 8. In detail, the Young's modulus of the reference TPU sample was $63 \pm 2 \mathrm{MPa}$, accompanied with an elongation at a break of $230 \%$, while the incorporation of $30 \mathrm{wt} \%$ TR dropped the mechanical properties progressively to 6.3 MPa with an elongation at break of only $55 \%$. In the same aspect, the impact strength 
decreased more than $50 \%$, where the TR content was greater than $10 \mathrm{wt} \%$, as presented in Table 4.

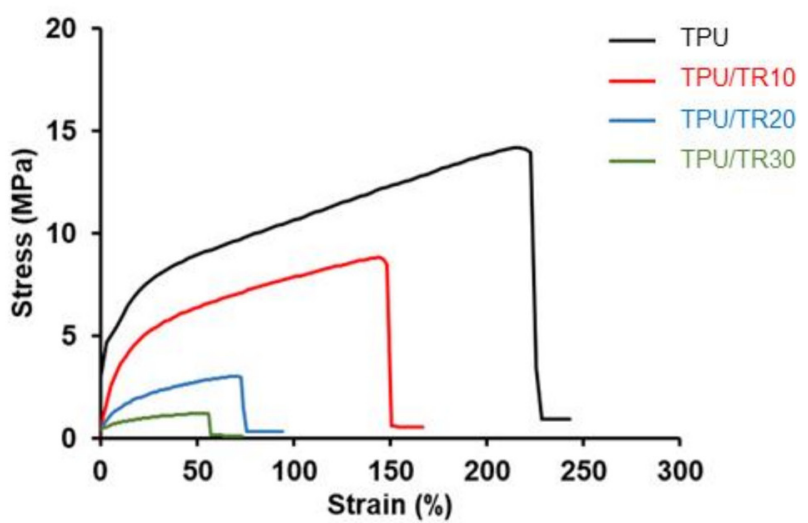

A

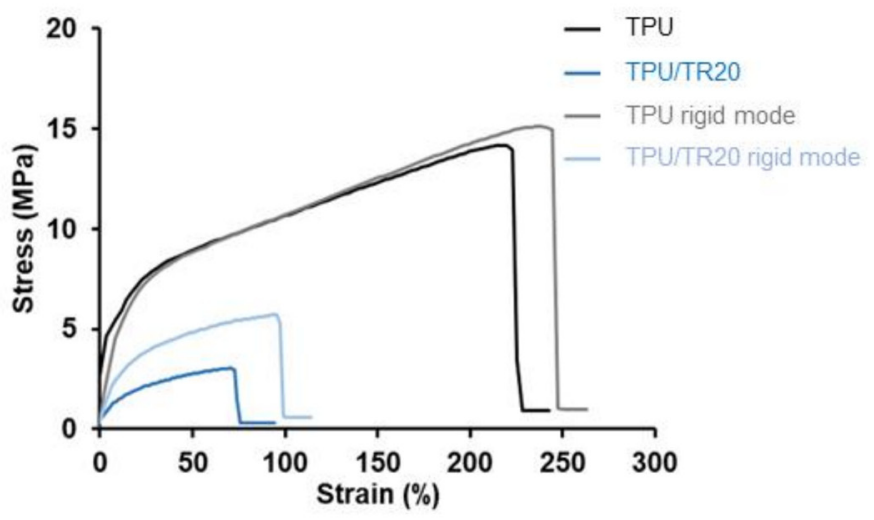

B

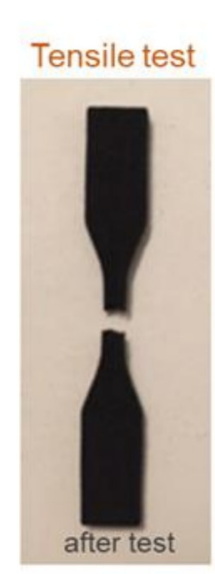

Impact

strength test

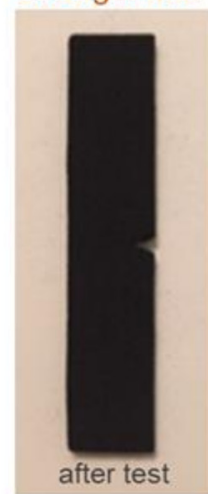

C

Figure 8. Stress-strain curves of TPU(/TR) samples produced by flex (A) and rigid (B) mode printing. Digital images after tensile and impact strength tests $(\mathbf{C})$.

Table 4. Tensile and impact strength tests results of TPU/TR printed materials.

\begin{tabular}{|c|c|c|c|c|}
\hline Sample & $\begin{array}{l}\text { Young's Modulus } \\
\text { (MPa) }\end{array}$ & Stress at Yield (MPa) & $\begin{array}{c}\text { Elongation at Break } \\
(\%)\end{array}$ & $\begin{array}{c}\text { Impact Resistance } \\
\left(\mathrm{kJ} / \mathrm{m}^{2}\right)\end{array}$ \\
\hline \multicolumn{5}{|c|}{ Classic printing conditions } \\
\hline TPU & $63 \pm 2$ & $13 \pm 0.9$ & $228 \pm 5$ & $22.6 \pm 2.4$ \\
\hline TPU/TR10 & $44 \pm 1$ & $8.1 \pm 0.5$ & $148 \pm 6$ & $14.8 \pm 1.8$ \\
\hline TPU/TR20 & $14.5 \pm 1$ & $2.7 \pm 0.2$ & $76 \pm 3$ & $5.0 \pm 0.5$ \\
\hline TPU / TR30 & $6.3 \pm 1$ & $1.2 \pm 0.1$ & $55 \pm 3$ & $2.8 \pm 0.2$ \\
\hline \multicolumn{5}{|c|}{ 'Rigid mode' printing conditions } \\
\hline TPU rigid mode & $62.5 \pm 1$ & $12.9 \pm 2.2$ & $235 \pm 11$ & $26.6 \pm 3$ \\
\hline TPU/TR20 rigid mode & $31 \pm 1$ & $5.4 \pm 0.4$ & $100 \pm 8$ & $12 \pm 1$ \\
\hline
\end{tabular}

To understand the reason behind the significant drop in the TPU mechanical properties, we started to evaluate the morphological characteristics of the printed materials. As presented in Figure 9, the composite samples presented suitable dispersion of the rubber particles and a significant degree of interconnected pores. It was found that the printed TPU samples have a degree of porosity of $11 \%$, which increased to $15.4 \%$ and even up to $40.2 \%$ for TR content of 10 and $20 \mathrm{wt} \%$, respectively (Table 5). Since the volume and the shape of the printed and tested specimens is the same for all compositions, the increase in the 
material porosity imposed a decrease in the content of material per volume, thus leading to a decrease in the amount of material stressed during the mechanical test. The presence of such voids also plays the role of a structural defect that may readily induce mechanical failure. An improvement in the TPU/TR sample mechanical properties requires additional densification of the material, meaning a decrease in the degree of porosity. Therefore, we focused our attention on the system containing $20 \mathrm{wt} \%$ TR powder and prepared a series of samples (pristine TPU and TPU/TR20) using a new printing mode, described as 'rigid mode'. In fact, Sinterit ${ }^{\circledR}$ printing software offers the possibility of increasing laser power while conserving the same printing layer thickness and conditions. As a result, the applied 'rigid mode' enabled us to reduce the porous volume for the TPU/TR20 from $40 \%$ to $29 \%$ (Table 5). This change improved the material mechanical properties where the Young's modulus values were increased from $14.5 \mathrm{MPa}$ to $31 \mathrm{MPa}$, accompanied by a respective increase in the elongation at break (from $76 \%$ to $100 \%$ ) and a significant enhancement of the material impact resistance from $5 \mathrm{~kJ} / \mathrm{m}^{2}$ to $12 \mathrm{~kJ} / \mathrm{m}^{2}$. It is important to mention that applying 'rigid mode' did not affect neither the porosity nor the mechanical properties of the pristine TPU. Porosity remained around $12 \%$, while the impact strength increased slightly from ca. 23 to $26 \mathrm{~kJ} / \mathrm{m}^{2}$.

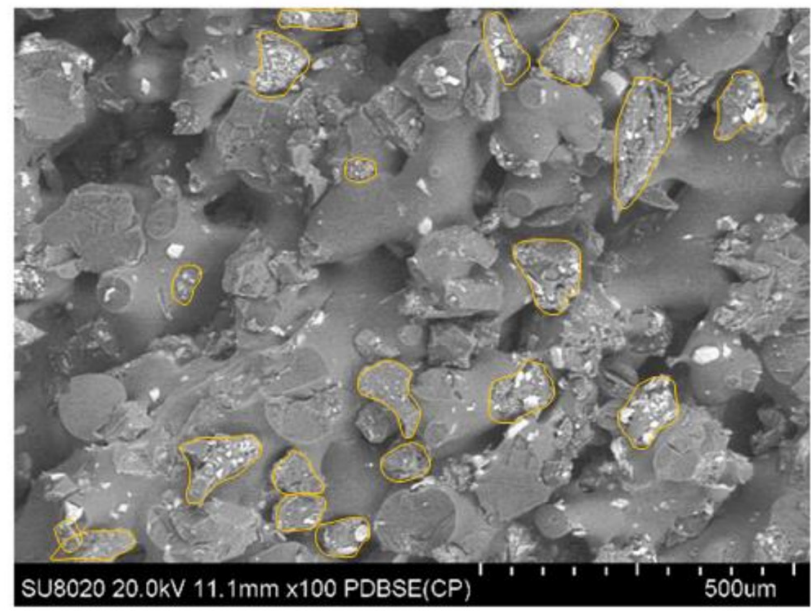

A

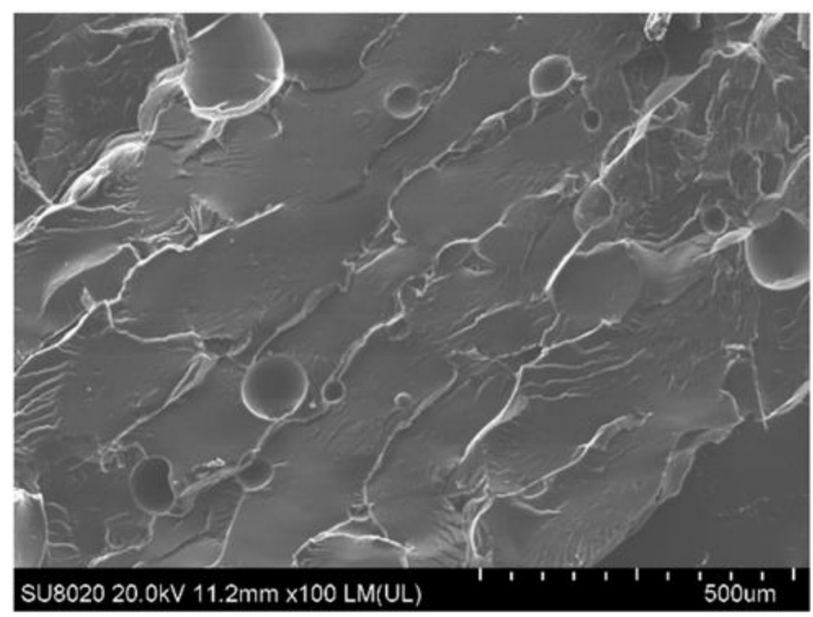

B

Figure 9. SEM micrographs of TPU/TR20 (TR particles enclosed in orange) (A) and TPU (B) printed sample.

Table 5. TPU-based printed sample porosity.

\begin{tabular}{|c|c|}
\hline Sample & Porosity (\%) \\
\hline \multicolumn{2}{|c|}{ Classic printing conditions } \\
\hline $\mathrm{TPU}^{1}$ & 11.0 \\
\hline TPU/TR10 2 & 15.4 \\
\hline TPU $/$ TR20 ${ }^{3}$ & 40.2 \\
\hline \multicolumn{2}{|c|}{ 'Rigid mode' printing conditions } \\
\hline $\mathrm{TPU}^{1}$ & 12.0 \\
\hline TPU/TR10 2 & n.a. \\
\hline TPU $/ \mathrm{TR} 20^{3}$ & 29.1 \\
\hline
\end{tabular}

The degree of porosity is referenced to: ${ }^{1}$ injected TPU; ${ }^{2}$ injected TPU containing $10 \mathrm{wt} \%$ TR powder; ${ }^{3}$ injected TPU containing $20 \mathrm{wt} \%$ TR powder.

In summary, for this section, it came out that SLS as an additive manufacturing approach can also be applied to produce elastomeric TPU-based materials with a high loading ratio of the recycled TR (up to $20 \mathrm{wt} \%$ ) with a fine surface finish of the samples. In addition to the suitable distribution of the TR within the polymer matrix, a certain degree of porosity was however observed throughout the sample volume. Overall, the amount 
of the incorporated rubber particles and the thermal stability of the samples were not impacted after the printing procedure.

The composite materials presented suitable impact strength properties that can be easily tuned with the applied printing conditions.

The progress made in the present study allowed us to go one step forward in the prototyping of devices with desired properties and functionalities. The authors would like to underline the advantage of the printing approach, in comparison to conventionally used methods (e.g., injection molding, thermal compression, or others), mainly in the possibility to generate objects with a complex three-dimensional shape, without the fabrication and use of complex molds composed of multiple pieces. Moreover, the economic impact in the valorization of the composite materials, without the generation of an additional waste during the printing process, is also a criterion that should not be neglected. As presented in Figure 10, functional parts such as replete wheel and complex mechanical pieces for the building of complex mechanical mechanisms based on PA12/TR20 were successfully fabricated by SLS, as well as porous compressible insole from TPU/TR20 that could be subjected to compression forces. With this, it was demonstrated that it is possible to produce functional materials containing a high loading ratio of the used TR by suitably combining its properties within appropriate polymer matrices.

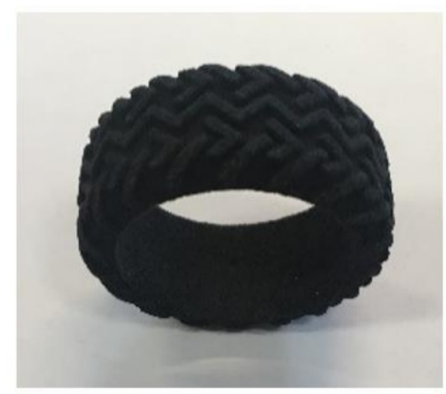

A

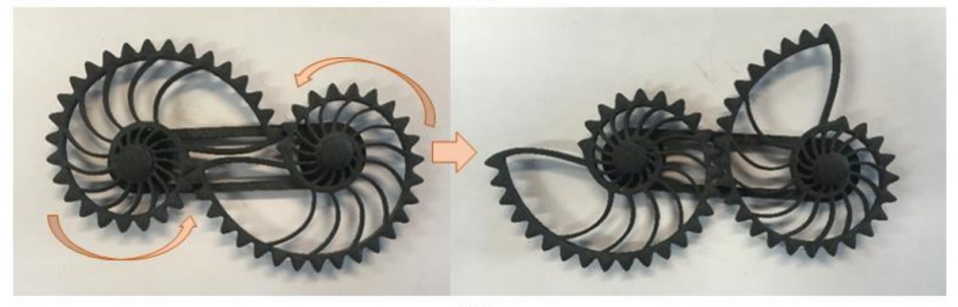

$\mathrm{C}$

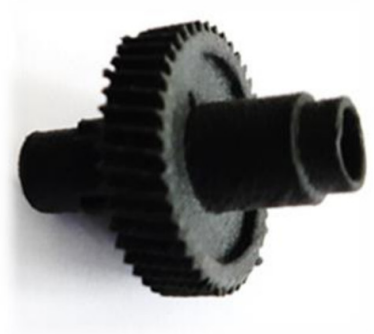

$\mathrm{B}$

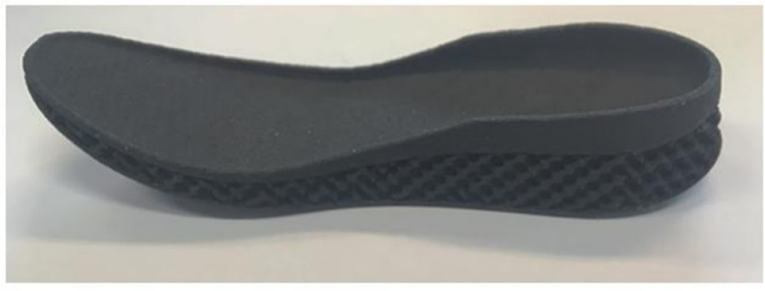

$\mathrm{D}$

Figure 10. Digital photos of composite prototypes printed by SLS: tire and complex mechanical parts based on PA12/TR20 (A-C) and porous flexible insole based on TPU/TR20 (D).

\section{Conclusions}

In summary, additive manufacturing technologies such as SLS were proposed as a suitable solution for the incorporation of recycled TR (up to $30 \mathrm{wt} \%$ ) into PA12 and TPUbased materials with conferred shape, chemical composition, and mechanical properties. Overall, both the PA12 and TPU composites were characterized by a suitable distribution of the rubber filler within the matrix and a controlled amount of the incorporated TR powder. In addition, the PA12/TR materials presented suitable mechanical properties even at high TR loading, while the TPU/TR composites were characterized with suitable impact strength. Some examples of fast prototyping were also demonstrated, such as PA12/TR20-based complex mechanical parts, as well as porous and flexible insole from TPU/TR20. With this study, new aspects of the recycled TR valorization and reuse for polymer composites fabrication with promising applications were outlined, proposing SLS as a flexible additive manufacturing technique. As a final remark, both materials chemical composition and printing conditions should be considered for the preparation of 
such composite materials in order to properly combine the polymer and recycled rubber properties for conferred physicomechanical properties of the final devices.

Author Contributions: Conceptualization, F.L. and A.T.; methodology, L.B.; software, L.B.; validation, L.B., A.T., and F.L.; formal analysis, L.B. and A.T.; investigation, L.B.; resources, A.T. and F.L.; data curation, L.B., A.T., and F.L.; writing-original draft prepara-tion, A.T.; writing-review and editing, F.L., A.T., and P.D.; visualization, F.L. and A.T.; supervision, A.T. and F.L.; project administration, F.L.; funding acquisition, F.L. All authors have read and agreed to the published version of the manuscript.

Funding: This research was supported by the Greener fund and King Baudouin Foundation (Belgium) (2019-2020) through the VALPREMA-3D project.

Institutional Review Board Statement: Not applicable.

Informed Consent Statement: Not applicable.

Data Availability Statement: Not applicable.

Conflicts of Interest: The authors declare no conflict of interest.

\section{References}

1. Goodyear, C. Improvement in India-Rubber Fabrics. U.S. Patent 3,462, 9 March 1844.

2. Sienkiewicz, M.; Kucinska-Lipka, J.; Janik, H.; Balas, A. Progress in used tyres management in the European Union: A review. Waste Manag. 2012, 32, 1742-1751. [CrossRef] [PubMed]

3. Czajczyńska, D.; Krzyżyńska, R.; Jouhara, H.; Spencer, N. Use of pyrolytic gas from waste tire as a fuel: A review. Energy 2017, 134, 1121-1131. [CrossRef]

4. Adhikari, B. Reclamation and recycling of waste rubber. Prog. Polym. Sci. 2000, 25, 909-948. [CrossRef]

5. Ferrao, P.; Ribeiro, P.; Silva, P. A management system for end-of-life tyres: A Portuguese case study. Waste Manag. 2008, 28, 604-614. [CrossRef]

6. Roche, N.; Ichchou, M.; Salvia, M.; Chettah, A. Dynamic Damping Properties of Thermoplastic Elastomers Based on EVA and Recycled Ground Tire Rubber. J. Elastomers Plast. 2011, 43, 317-340. [CrossRef]

7. Amari, T.; Themelis, N.J.; Wernick, I.K. Resource recovery from used rubber tires. Resour. Policy 1999, 25, 179-188. [CrossRef]

8. Zheng, S.; Liao, M.; Chen, Y.; Brook, M.A. Dissolving used rubber tires. Green Chem. 2019, 22, 94-102. [CrossRef]

9. Xu, H.; Fan, T.; Ye, N.; Wu, W.; Huang, D.; Wang, D.; Wang, Z.; Zhang, L. Plasticization Effect of Bio-Based Plasticizers from Soybean Oil for Tire Tread Rubber. Polymers 2020, 12, 623. [CrossRef]

10. Chiang, T.; Liu, H.-L.; Tsai, L.-C.; Jiang, T.; Ma, N.; Tsai, F.-C. Improvement of the mechanical property and thermal stability of polypropylene/recycled rubber composite by chemical modification and physical blending. Sci. Rep. 2020, 10, 1-8. [CrossRef]

11. Alkadi, F.; Lee, J.; Yeo, J.-S.; Hwang, S.-H.; Choi, J.-W. 3D Printing of Ground Tire Rubber Composites. Int. J. Precis. Eng. Manuf. Technol. 2019, 6, 211-222. [CrossRef]

12. Quetzeri-Santiago, M.A.; Hedegaard, C.; Castrejón-Pita, J.R. Additive Manufacturing with Liquid Latex and Recycled End-of-Life Rubber. 3D Print. Addit. Manuf. 2019, 6, 149-157. [CrossRef]

13. Mazzoli, A.; Moriconi, G.; Pauri, M.G. Characterization of an aluminum-filled polyamide powder for applications in selective laser sintering. Mater. Des. 2007, 28, 993-1000. [CrossRef]

14. Zhu, W.; Yan, C.; Shi, Y.; Wen, S.; Liu, J.; Wei, Q.; Shi, Y. A novel method based on selective laser sintering for preparing high-performance carbon fibres/polyamide12/epoxy ternary composites. Sci. Rep. 2016, 6, 33780. [CrossRef] [PubMed]

15. Chung, H.; Das, S. Functionally graded Nylon-11/silica nanocomposites produced by selective laser sintering. Mater. Sci. Eng. A 2008, 487, 251-257. [CrossRef]

16. Jain, P.K.; Pandey, P.M.; Rao, P. Selective laser sintering of clay-reinforced polyamide. Polym. Compos. 2009, 31, 732-743. [CrossRef]

17. Chung, H.; Das, S. Processing and properties of glass bead particulate-filled functionally graded Nylon- 11 composites produced by selective laser sintering. Mater. Sci. Eng. A 2006, 437, 226-234. [CrossRef]

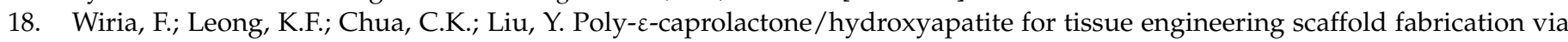
selective laser sintering. Acta Biomater. 2007, 3, 1-12. [CrossRef]

19. Sunthonpagasit, N.; Duffey, M.R. Scrap tires to crumb rubber: Feasibility analysis for processing facilities. Resour. Conserv. Recycl. 2004, 40, 281-299. [CrossRef]

20. Ismail, H.; Awang, M.; Hazizan, M.A. Effect of Waste Tire Dust (WTD) Size on the Mechanical and Morphological Properties of Polypropylene/Waste Tire Dust (PP/WTD) Blends. Polym. Technol. Eng. 2006, 45, 463-468. [CrossRef]

21. Colom, X.; Cañavate, J.; Carrillo, F.; Suñol, J.J. Effect of the particle size and acid pretreatments on compatibility and properties of recycled HDPE plastic bottles filled with ground tyre powder. J. Appl. Polym. Sci. 2009, 112, 1882-1890. [CrossRef]

22. Mujal-Rosas, R.; Orrit-Prat, J.; Ramis-Juan, X.; Marín-Genescà, M.; Rahhali, A. Study on dielectric, thermal, and mechanical properties of the ethylene vinyl acetate reinforced with ground tire rubber. J. Reinf. Plast. Compos. 2011, 30, 581-592. [CrossRef] 
23. Tantayanon, S.; Juikham, S. Enhanced toughening of poly(propylene) with reclaimed-tire rubber. J. Appl. Polym. Sci. 2004, 91, 510-515. [CrossRef]

24. Goodridge, R.; Tuck, C.; Hague, R. Laser sintering of polyamides and other polymers. Prog. Mater. Sci. 2012, 57, 229-267. [CrossRef]

25. Colom, X.; Cañavate, J.; Carrillo-Navarrete, F.; Velasco, J.; Pagès, P.; Mujal, R.; Nogués, F. Structural and mechanical studies on modified reused tyres composites. Eur. Polym. J. 2006, 42, 2369-2378. [CrossRef]

26. Sonnier, R.; Leroy, E.; Clerc, L.; Bergeret, A.; Lopez-Cuesta, J. Compatibilisation of polyethylene/ground tyre rubber blends by $\gamma$ irradiation. Polym. Degrad. Stab. 2006, 91, 2375-2379. [CrossRef]

27. Punnarak, P.; Tantayanon, S.; Tangpasuthadol, V. Dynamic vulcanization of reclaimed tire rubber and high density polyethylene blends. Polym. Degrad. Stab. 2006, 91, 3456-3462. [CrossRef] 